\title{
Recovery after prolonged treatment in the intensive care unit
}

\author{
Matteo Parotto MD PhD, Margaret S. Herridge MD MSc MPH
}

Cite as: CMAJ 2020 November 30;192:E1637. doi: 10.1503/cmaj.201356

\section{1}

Prolonged length of stay in intensive care units (ICUs) is associated with long-term disability

About $25 \%-80 \%$ of patients admitted to an ICU will have new or worsened physical, cognitive or mental health impairments that persist beyond discharge from the hospital. ${ }^{1,2}$ In those with a prolonged length of stay, defined as 1 week or longer of mechanical ventilation, patient age and length of stay in an ICU affect motor and cognitive functional dependency at 1 year after discharge from the ICU, independent of the admitting diagnosis and illness severity. ${ }^{3}$

2

Physical impairments after critical illness can last for years

Protracted exposure to sedation, paralytics and immobility in the context of severe catabolic illness leads to specific nerve and muscle injury, which together comprise ICU-acquired weakness. ${ }^{2}$ This affects $25 \%-50 \%$ of patients discharged from the ICU and persists after hospital discharge, lasting more than 24 months in about $10 \%$ of cases. Fatigue, joint contractures and peripheral nerve injuries are frequently reported, affecting activities of daily living, including grooming, feeding, bathing and walking. ${ }^{2}$

\section{Cognitive dysfunction develops in about one-third of patients ${ }^{2}$}

Of similar magnitude to mild dementia or moderate traumatic brain injury, cognitive dysfunction affecting memory, attention, problem solving and execution of complex tasks persists in about one-third of patients 1 year after discharge form the ICU. ${ }^{4}$

\section{4}

Mental health disorders can develop in both patients and

caregivers

Anxiety, depression and posttraumatic stress disorder occur in about $25 \%-35 \%$ of patients and $60 \%-70 \%$ of their caregivers. ${ }^{4,5}$ Although risk factors, such as old age or cognitive impairment have been described, individuals without predisposing conditions are also at risk for longlasting sequelae. ${ }^{3}$

\section{Tailored and graduated rehabilitation can help, but recovery} may be incomplete

No robust intervention has been shown consistently to improve recovery after prolonged ICU stay. ${ }^{2}$ A comprehensive multidisciplinary approach that includes rehabilitation specialists, psychiatrists and neurologists may be required and continue after hospital discharge. ${ }^{2}$

\section{References}

1. Herridge MS, Tansey CM, Matté A, et al.; Canadian Critical Care Trials Group. Functional disability 5 years after acute respiratory distress syndrome. N Engl J Med 2011;364:1293-304.

2. Needham DM, Davidson J, Cohen $\mathrm{H}$, et al. Improving longterm outcomes after discharge from intensive care unit: report from a stakeholders' conference. Crit Care Med 2012;40:502-9.

3. Herridge MS, Chu LM, Matte A, et al.; RECOVER Program Investigators. (Phase 1: towards RECOVER); Canadian Critical Care Trials Group. The RECOVER Program: disability risk groups and 1-year outcome after 7 or more days of mechanical ventilation. Am J Respir Crit Care Med 2016;194:831-44.

4. Pandharipande PP, Girard TD, Jackson JC, et al.; BRAIN-ICU Study Investigators. Long-term cognitive impairment after critical illness. N Engl J Med 2013;369:1306-16.

5. Cameron JI, Chu LM, Matte A, et al.; RECOVER Program Investigators. (Phase 1: towards RECOVER); Canadian Critical Care Trials Group. One-year outcomes in caregivers of critically ill patients. N Engl J Med 2016;374:1831-41.

Competing interests: None declared.

This article has been peer reviewed.

Affiliations: Department of Anesthesia (Parotto) and Interdepartmental Division of Critical Care Medicine (Parotto, Herridge), University of Toronto; Department of Medicine (Herridge), University Health Network, Toronto, Ont.

Correspondence to: Matteo Parotto, matteo.parotto@uhn.ca

CMAJ invites submissions to "Five things to know about ..." Submit manuscripts online at http://mc. manuscriptcentral.com/cmaj 